\title{
Erratum to: Micromachined Coulter counter for dynamic impedance study of time sensitive cells
}

\author{
Yifan Wu • Xu Han • James D. Benson • Mahmoud Almasri
}

Published online: 26 August 2012

(C) Springer Science+Business Media, LLC 2012

Erratum to: Biomed Microdevices (2012) 14:739-750

DOI 10.1007/s10544-012-9655-6

$\mathrm{Xu}$ Han should be listed in the original publication of this article as the second author, his affiliation is "University of Missouri, Columbia, USA", and the correct author list is shown above.

The online version of the original article can be found at http:// dx.doi.org/10.1007/s10544-012-9655-6.

Y. Wu $\cdot$ X. Han $\cdot$ J. D. Benson $\cdot$ M. Almasri $(\bowtie)$

University of Missouri,

Columbia, MO, USA

e-mail: almasrim@missouri.edu 